\title{
Using Primo for undergraduate research: a usability study
}

\author{
Greta Kliewer, University of Kansas \\ Amalia Monroe-Gulick, University of Kansas \\ Stephanie Gamble, University of Kansas \\ Erik Radio, University of Arizona
}

\section{Introduction}

The University of Kansas (KU) Libraries has employed the Primo web-scale discovery interface since fall 2012. An Ex Libris product, Primo provides a subscription index of online content from various providers. A prominent feature of Primo is the single search box feature on its primary interface, a style widely used by commercial search engines. The present study builds upon two previous usability studies at KU that examined graduate and undergraduate use of the tool, targeted major issues with the interface, and tested users' ability to complete both open-ended and, to a larger extent, known-item search tasks (Hanrath and Kottman, 2015). By contrast, the current study was focused on observing and analyzing how students used Primo in an open-ended search scenario, and how well it performed in meeting user expectations and needs.

Conducted in the spring of 2015, the current study analyzes undergraduate patrons' informationseeking habits within the Primo interface. Undergraduates make up the largest user group of KU Libraries, and library instructors often use or discuss Primo in library instruction sessions that deal with research topics at an introductory level. The prominent Primo search box on KU Libraries' home page is an entry point for students as well if they are already using the Libraries' resources for a project.

Consequently, this usability study attempts to provide a better understanding of undergraduates' use of Primo, specifically in a more open-ended setting. While many studies discussed below have focused on the use of Primo for known-item searching, none focus solely on open-ended searching. An examination of this type of search scenario is warranted since it is a common research situation. The research questions this study aimed to answer include:

- How do undergraduates approach and conduct academic research using Primo or other tools?

- What strengths and weaknesses of Primo did students encounter while completing an openended research task?

- What implications do our findings have for future use of Primo in academic research at the undergraduate level?

\section{Literature Review}

When undergraduates begin a research assignment they are often unaware how much information exists on a topic and may browse library resources while formulating an approach to their research 
(Gustavsson and Karlsson, 2015). Web-scale discovery tools have changed students' expectations for this process (Majors, 2012). Undergraduates are accustomed to finding the information they need in a disintermediated environment. The information they seek is available instantaneously and often without the assistance of a librarian or other mediator (Rempel et al, 2013). Academic libraries rely on index-based discovery services to make their resources accessible to patrons who are used to retrieving information via Google and other single-search box environments (Breeding, 2015). Web-scale discovery tools provide a starting point that allows students to begin research without knowing how to use the library catalog, specific databases, or other library resources with which they may not be familiar (RoseWiles and Hofmann, 2013).

A considerable body of literature has been devoted to the usability and impact of web-scale discovery tools since their inception in 2007. A small but notable number of these studies have focused specifically on Primo, centering on trends in users' ability to learn the interface and the successes and frustrations they encountered (Nichols et al, 2014). Sadeh (2008) conducted a usability study on the beta version of Primo in which users demonstrated positive attitudes and willingness to learn the tool, as well as an appreciation for facets that allowed them to filter large amounts of search results. In two subsequent studies, users reported high satisfaction with Primo despite difficulty completing complex research tasks (Hanrath and Kottman, 2015). Sadeh's and Comeaux's studies, as well as Jarret (2011), all indicated that users had positive experiences regarding ease of use, effectiveness, and search results relevance, as well as exhibiting greater use of facets and other refining tools as search tasks increased in complexity (Nichols et al., 2014). Niu et al. compared use of Primo to that of VuFind using log analysis. They found that users relied heavily on search defaults, using facets to limit results in only 9.7 percent of searches in Primo. They reported that users applied minimum effort in searching, conducting broad keyword searches consistent with use of search engines like Google (Niu et al., 2014). Hanrath and Kottman (2014) found that undergraduate and graduate students at KU rated Primo positively while success rates for common library research tasks ranged from 70 to 88 percent. They indicated that factors beyond the Primo interface such as use of link resolvers and publishers' interfaces, as well as students' skill levels may have influenced their success in the study's tasks. Finally, Brett et al. (2016) conducted a similar Primo usability study that included some open-ended search tasks, noting that users were able to successfully retrieve items through Primo but usually did not make full use of all available features and facets that could have aided in this process.

Literature regarding other web-scale discovery tools also informed the context and design of this study. Much of this literature has focused on comparisons among discovery tools (Asher et al., 2013; Niu et al., 2014), or usability of a single interface (Lown et al., 2013). Common issues in the literature regarding web-based discovery tools include ambiguity as to what resources are indexed, a lack of transparency regarding algorithms for relevance ranking of indexed materials (Kelley, 2012), and that retrieving the full text of an article is sometimes unintuitive and involves navigating multiple interfaces (Dalal et al., 2015). Librarians observed that students sometimes did not always understand the indexing in webscale discovery tools, and failed to apply advanced search techniques or evaluation criteria (Dalal et al., 2015). While these articles focused on usability of the tools' interfaces, few included direct student feedback as part of the study - an increasingly important component for evaluation as these tools evolve (Lundrigan et al., 2015).

Library instruction has changed with the evolution of web-scale discovery (Gustavsson and Karlsson, 2015). Since many students are used to retrieving information in a "Google-like" environment, web- 
scale discovery tools present instructors with opportunities to meet students in a familiar search environment. Using a web-scale discovery tool has the potential to free up time that was previously spent instructing students on the use of subject-specific databases (Cmor and Li, 2012). Seeber (2015) posits that the large amount of search results returned by these types of tools necessitates a focus on engaging students in the evaluation of information, focusing more on the research process than individual tools. This type of instruction moves beyond learning specific databases, and has the potential to remain relevant after their research assignments are completed (Seeber, 2015; Gustavsson and Karlsson, 2015).

\section{Methodology}

The authors recruited participants via the Libraries' social media accounts, and by soliciting members of its Student Advisory Board. Study participants included 10 freshmen, six sophomores, nine juniors, and five seniors from a variety of disciplines. These disciplines fell into three general categories: 14 in the STEM fields, 11 in the social sciences, and five in the humanities. Thirty-one students took part in the usability study. One corrupted recording file resulted in 30 valid cases to analyze.

The study utilized a mixed methods approach by collecting both qualitative and quantitative data. The search actions and demographic information of the students was collected, allowing for correlational analyses. In addition, both the verbal narration of the search session itself, and the comments in the follow-up survey, provided a rich amount of qualitative data. Throughout the discussion this data is included to help explain and further understand students' thoughts and experiences with research. Each student met individually with one or two librarians who facilitated the session. Facilitators began by providing students with a sample assignment prompt regarding social media and privacy as a topic that would be familiar to undergraduates of all levels (see Appendix A). Participants were instructed to use any tool they considered helpful to find resources that would be appropriate for inclusion in a 5-10 page academic paper on the topic. Students were encouraged to narrate their thoughts and actions as they navigated various online tools to find resources. The model for this assignment was derived from similar assignments KU's instruction librarians had encountered in working with undergraduate coursework. The authors used TechSmith's Morae software to record audio, screen display, keystrokes, and mouse clicks. If students did not navigate to Primo on their own within the first 10 minutes of the session, librarians prompted them to do so for the remainder of the session. When students finished searching a survey link was provided to collect feedback about students' experience using Primo (see Appendix C). To avoid any breach of confidentiality, each student was assigned a unique participant number.

\section{Limitations}

The study was subject to various limitations. First, the 30 participants were only observed for 30 minutes each. This is a small sample at a school of approximately 17,300 undergraduates. Though a small sample, the qualitative and quantitative data collected did help inform KU Libraries' own perception of user habits as well as allow other researchers to "make judgements about the findings' transferability to different settings or contexts (Zhang and Wildemuth, 2009)." Usability tests with only 20 users can yield statistically significant results within a 90 percent confidence interval (Nielsen, 2006). Still, because it was unclear whether student attitudes towards Primo were reaching saturation, the data gathered via survey and screen capture in this study was most useful in establishing a general picture of undergraduate patterns of Primo usage. Unfortunately, there was little room to make definitive 
statements about how students' academic year or discipline of study may have contributed to their use of Primo.

In addition, it is difficult to present a definitive picture of how Primo contributes to undergraduates' research progress with only a 30-minute interval. It was beyond the scope of this study to investigate the degree to which the students would have improved upon their research given additional time. Students' success on the research task was based on the behavior observed in the study, making speculation regarding their evolving practices on similar tasks an inconclusive factor.

Finally, usability sessions took place in the library, and librarians elicited feedback from the participants. This specific environment may have prompted students to respond in ways they perceived librarians would consider "correct" rather than working as they would have in a different environment.

\section{Findings and Discussion}

\section{Open-ended searching}

These results indicate students' strong preference for beginning a research project with broader searches, browsing resources to see what information is available (Gustavsson and Karlsson, 2015). Similarly, the results indicate that within the group only three students conducted a known-item search during their session, only one doing so more than once. These types of known-item searches constituted less than 1 percent of all searches, indicating, somewhat predictably, that students begin research assignments with an open-ended approach. Much of the literature dedicated to usability of web-scale discovery services focuses on known-item searching. By contrast, this study focused on students' natural search habits, which consisted largely of open-ended searching using subject and keyword terms. In the previous two usability studies conducted at KU, students completed one open-ended search task and three known-item tasks. The rate of success in the open-ended tasks was higher than for the knownitem tasks by nearly 8 percent. It is important to note that in the majority of scenarios students did not have a known item in mind when given the prompt, further suggesting that known-item searching is not an entirely common research strategy for this user group. Discovery is a key function of tools like Primo that allow users to encounter resources they may have not previously known existed. Successful discovery tools are those that adapt to users' expectations and provide relevant resources (Namei and Young, 2015). This study enabled the authors to observe students' expectations and behaviors as well as to examine the relevance of resources discovered in order to evaluate Primo's overall performance in the context in which students most commonly use it.

\section{Preference for Primo}

Students completed approximately 30 percent of their total searches in Primo. This percentage may have been lower if they had not been prompted to use Primo. Students were clearly familiar with Primo since only one had not used it before the study, and 57 percent used it in the first 10 minutes without prompting. However, even with prompting, that searches conducted in Primo represented only a third of the study's total searches suggests that Primo is not necessarily students' default or preferred tool for conducting research. While nine students chose Primo as their starting point for searching, 12 began searching in Google or another search engine. Finally, another five used Google Scholar to see what general information they could find on their topic in order to find resources or more keywords. Students 
used keywords gleaned from the web to improve their searches in Primo, which they perceived as a source of reputable information. Many students navigated back and forth between Primo and other sources throughout their session, building on the information and terms they encountered as they progressed. Given the open-ended nature of this scenario it is not unexpected that students went first to commercial search engines for their ease of use, but it is interesting that slightly more than half did eventually go to Primo of their own volition. For those that did not it would be an interesting study to see at which point, if any, they went to a library search tool, and what the nature of their failed searches with commercial engines looked like. These challenges might be taken into account when answering the question of what might be avoided in a library search interface.

\section{Search strategies}

Students conducted nearly all their searches using keywords or search phrases comprised of one to 10 terms, whether searching in Primo or not. The average student conducted 6.6 different searches during a 30-minute session, although the number per student ranged from two to 13 . In Primo, students' searches were a bit shorter on average at 4.1 terms in length. This behavior corresponds with students' comments that Primo provides a "Google-like" search, but yields what they perceived as reputable sources.

At the start of each session, the authors asked students to indicate which of the sources they examined they would have kept to read or cite for their assignment. A general pattern emerged in which students who conducted shorter search phrases on average used a higher percentage of the sources they examined. This is consistent with previous usability studies conducted on Primo at KU that indicated that students who used fewer search terms performed tasks more successfully (Hanrath and Kottman, 2015).

\section{Using search defaults}

Once in Primo, students preferred to search in the Quick Search tab, which is the default when navigating to Primo via the search box on the libraries' web page. Students reached 168 of the 268 unique sources they examined in Primo (63 percent) via Quick Search, while they retrieved another 38 percent via the Articles \& More tab. At KU, the search bar on the Libraries' Journals and Databases page searches the Articles \& More tab. This study did not record how many students reached this tab via the Journals and Databases page versus navigating to the tab from Quick Search, but this would be useful information to note, indicating whether students regularly change the defaults when searching in Primo. During the study, students only retrieved 1 percent of resources in Primo using the Books \& More tab. Of the 30 students in the study, only seven conducted searches in Primo using the Advanced Search box. These searches accounted for 13 percent of those searches conducted in Primo.

Some students expressed a vague understanding that their search results were based on an algorithm that pulled from the resources indexed in Primo, and that issues with finding relevant sources lay with this algorithm rather than their search process (e.g. one student mentioned that it "Sorts by 'relevance' but not exactly sure what that pertains to.") Students were quick to abandon a search if they did not find pertinent articles within the first page or two of results. One reasoned that they select a source if "[i]t's in the top 10 - I think those are usually the best" while another indicated that "I think the algorithm that it uses to get close to what you think is usually pretty good, but I guess I would never know because I never dig that far into it." Students often changed their search terms with little 
explanation after scanning the first page of results, preferring not to examine articles lower than the first ten results in 66 percent of Primo searches.

Use of Facets

Facets were of particular interest in this study as previous studies indicated that filtering the large amount of results provided by web-scale discovery tools can be one of the more challenging tasks students face when using these tools for research (Seeber, 2015). In this study, students expressed both satisfaction with the large amount of sources their searches returned, as well as frustration sifting through them for relevant resources. The researchers focused on students' use of the facets under "Narrow My Results" on the left side of the results screen, which include Format, Date, Topic, Author/Creator, Language, Article Database, etc. They also examined the use of Top Level facets listed along the top of the interface (see Figure 1). Of the 30 students in the study, 67 percent used at least one facet in a search to narrow their results in Primo.

Figure 1 - Image of Primo Interface
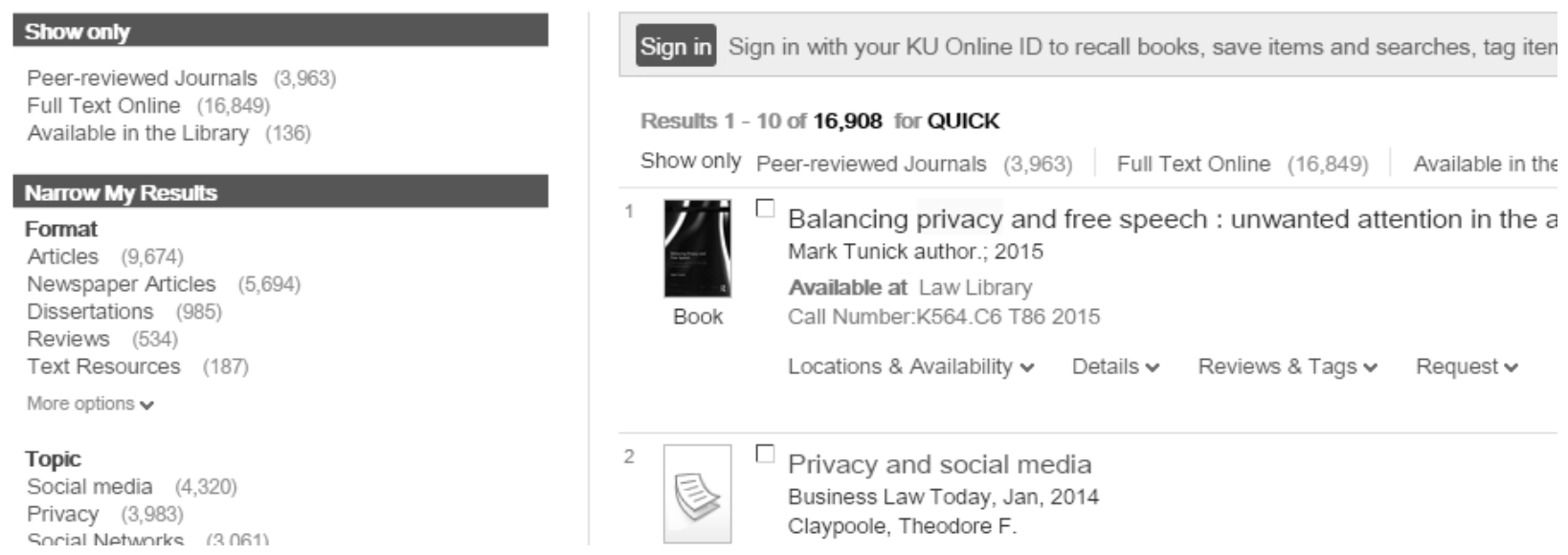

While approximately two-thirds of students used a facet in one or more of their searches, at least onethird of the participants did not move beyond Primo's default settings. Overlooking facets that would have improved their search was a common issue. One student commented in the session that they wished there were "a few limiters that relate more to the subject of the articles rather than the publication of the articles", overlooking the Topic facet on the left side of the screen. Another student overlooked the Full Text Online facet, commenting that, "I am not always sure that the source I want to use will be available immediately or on my computer." Students also exhibited some confusion about applying multiple facets to the same search:

When looking for more recent articles and sources, you have to sacrifice the relevancy, which can make research more difficult when you're getting sources that are newer, but have little to do with the topic you're looking at. Because you have to change your filter, you're giving up the usefulness of the "most recent" filter.

Of the 268 sources students examined in Primo, 72 percent were within the first page of results, with results limited to 10 per page. Twelve percent were within the second page, and two within the third. 
Only one participant used a resource from the fourth page of a search. Students examined 40 resources in Primo whose results ranking were not recorded. This behavior is consistent with findings that students tend to place their trust in the search tool's algorithm, tending to settle for resources from within the first page of results ( $\mathrm{Cmor}$ and $\mathrm{Li}, 2012$ ). This was consistent with concerns cited in the literature that poor search strategies lead students to sacrifice quality for "convenience, accessibility, or understandability, even after receiving library instruction (Rempel et al., 2013)." For an open-ended search environment, it is critical to acknowledge that most searches do not extend beyond the first page. For future research, it would be useful to observe how changes to an interface, such as providing more articles per page as a condensed method, affects students search tactics e.g. if they drop off after the first ten results or whether more resources might be taken into consideration.

Students used an average of 1.68 facets per session, though actual use of facets ranged from one to three per search - no single search contained more than three facets. Students conducted 91 searches in Primo that employed some combination of facets; this number includes repeated searches employed by multiple students. Sixty-two individual searches contained one facet, 17 contained a combination of two facets, and 12 used a combination of three facets.

Format was by far the most-used limiter; students applied it in 54 percent of faceted searches. They applied the Peer-Reviewed Journals and Date facets in 35 percent of faceted searches each, confirming comments that students were seeking recent, scholarly sources. Only two other facets received use during this study: Topic and Full Text Online (13 percent and 9 percent of faceted searches, respectively). Both these limiters apply to issues students brought up as frustrations: lack of pertinent articles, or struggling to retrieve full text items quickly.

\section{Strengths and weaknesses of searching in Primo}

General frustrations with Primo listed by students were varied (see Figure 2). In general they aligned with other common criticisms found in previous research studies discussed above, such as difficulty with filters, link resolvers, and other similar problems.

Figure 2 - Difficulties in Primo (Student Comments)

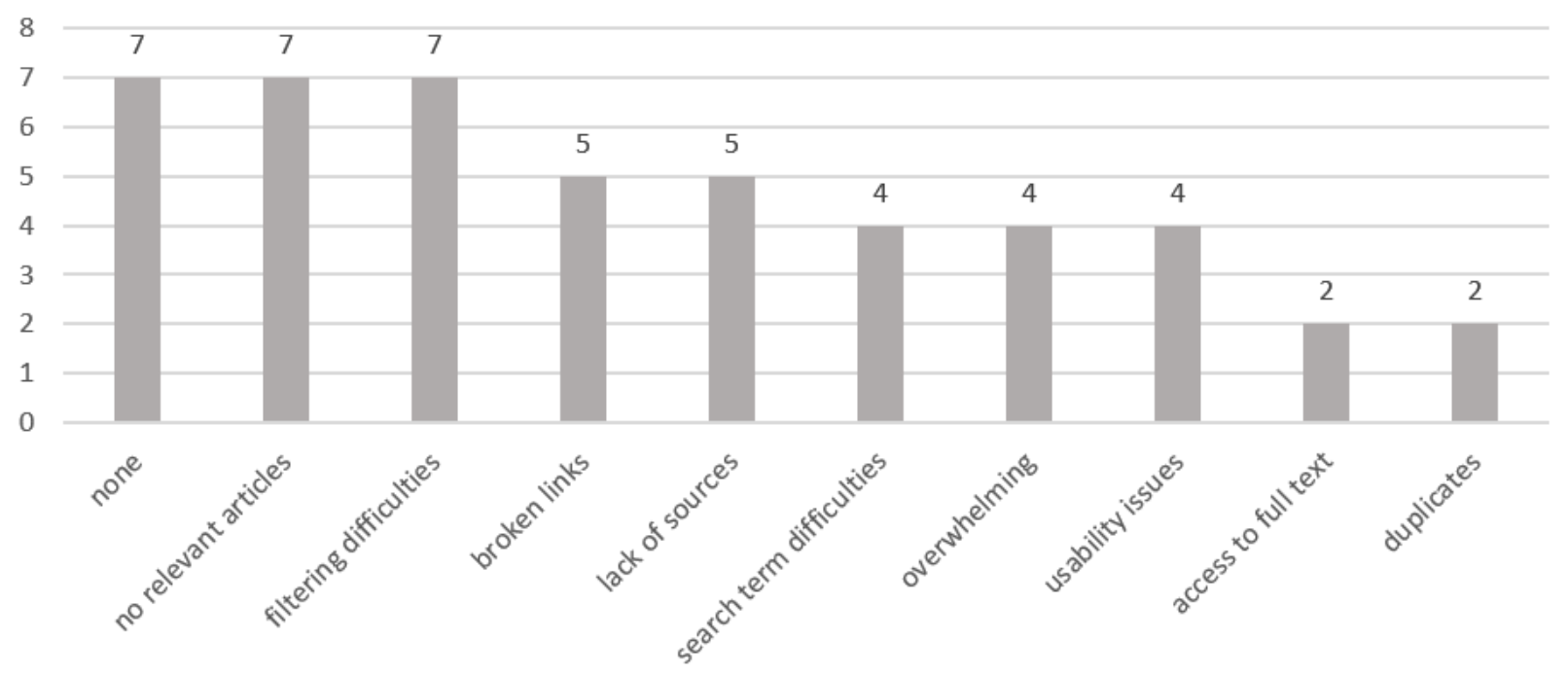


One of the most commonly cited concerns in the literature about web-scale discovery tools is that they provide so much information that it can be overwhelming and difficult to filter down to the most pertinent resources. This is particularly true for open-ended searching as there is no concrete 'goal' to be completed; success or the pursuit of more resources is subjectively determined. In this study students confirmed both the positive and negative aspects of this attribute of web-scale discovery. Four students said specifically that they found the interface to be overwhelming, while seven indicated they had issues filtering the data to find relevant results. One student (the only one to indicate they had "little" comfort using Primo for research) indicated that:

"[T] he first search result took me into a pandora's [sic] box of online downloads. The top seven results only had two items with direct pertinance [sic] to my topic. The search results seemed scattered and hard to sift through."

Another four mentioned they had issues figuring out what types of keywords to use in their searches. All students used almost exclusively keyword searches to find resources during this study. Students attempted to filter their results using facets with varying degrees of success (see above.) However, many were quick to abandon a confusing or overwhelming search after scanning the first page of results.

Seven students commented that Primo returned too few relevant articles based on their search, and five commented that there was a lack of resources in general. This may have resulted from not knowing how to construct appropriate searches, or from difficulty finding or using limiters.

\section{Misconceptions about nature of resources in Primo}

All 30 students indicated that Primo provided them appropriate resources for the research prompt. However, some students shared a misconception regarding the nature of the resources they were examining. These students assumed that because a resource was in Primo that it was a scholarly source. Nearly a third of students indicated that they liked using Primo for this reason ("There was a multitude of reputable resources and articles to search through"; "I liked that I knew the sources would be reliable and that I would not have to do more work to determine the validity of the sources"). This attitude confirms the concern expressed by some librarians that students place so much trust in the function of the tool that they do not conduct any additional criticism of their sources (Asher et al., 2013).

\section{Struggling to retrieve full-text items via the link resolver}

Half of the students encountered issues with the link resolver page at least once. In total, 23 searches included an instance where a student attempted to retrieve an article and was unable to do so due to broken links or confusion regarding the elements on the link resolver page, which opened in a new window. Aside from the broken links, students had several misconceptions regarding the link resolver. One was that the multiple links to an article's full-text displayed in the link resolver window were links to different articles, rather than the same article in different databases. The fact that many of these full text links, labeled "Article 1", "Article 2", etc. showed a date next to them representing the dates from which KU included the resource in their collection further enforced this misunderstanding. Students interpreted these dates as the publication dates of various articles, and would often choose the option with the most recent date range, perceiving it to be newer information. 
Another issue students encountered with the link resolver involved links from Primo to the journal itself rather than to a specific article. While some students understood what had happened and simply typed the article's title into the journal search to retrieve the article, others were confused and returned to the Primo interface. It was clear that when students clicked on an item in Primo they expected the link to connect them directly to the full text of an item, whether or not they had applied the full-text facet. When asked to describe their behavior upon encountering this issue, students responded with comments such as:

It gave me some complications so I thought l'd try another [link].

The first link doesn't really make sense after I've clicked on it. So I'm going to try to find a simpler way to analyze what this is trying to tell me...I feel like this would be a trustworthy place to find what I was looking for; I just have to find the way to find the information... This [abstract] speaks on an article, but I don't know how to find the article.

\section{Developing search strategies}

Employing over-simplified searches was a concern with web-scale discovery tools in the literature (Dalal et al., 2015). In this study, retrieving pertinent resources was the biggest challenge students reported, for several possible reasons. Nearly all students employed keyword searches, with strings of terms containing anywhere from one to eight terms. While students' search strategies may have been responsible for this lack of pertinent sources, only two acknowledged that this might be the case. One student acknowledged that, "I think that the search box itself doesn't have any issues. Sometimes the trick is using the right keyword, and it takes practice to see what is really useful for research, and what is unnecessary."

Positive attributes of Primo revolved around easy keyword searching, being able to navigate large amounts of information, having a single point to access multiple source types, and ease of locating what the students perceived to be relevant, reputable resources (see Figure 3). In addition to all 30 participants having positive comments about using the Primo interface, eight students also had no negative comments about their experience.

It should also be noted that 'pertinence' is not always initially evident in an open-ended search environment. What appears relevant may prove otherwise when examined in depth. Students are not usually evaluating an entire resource during an initial search process. Instead, as observed, they are gathering multiple resources that are evaluated later. Pertinence, then, may be more readily interpreted based on the type and quality of metadata presented to the user as it eliminates some amount of 'gambling' on the part of the user when relevance is not initially clear. 
Figure 3 - Positive Attributes of Primo (Student Comments)

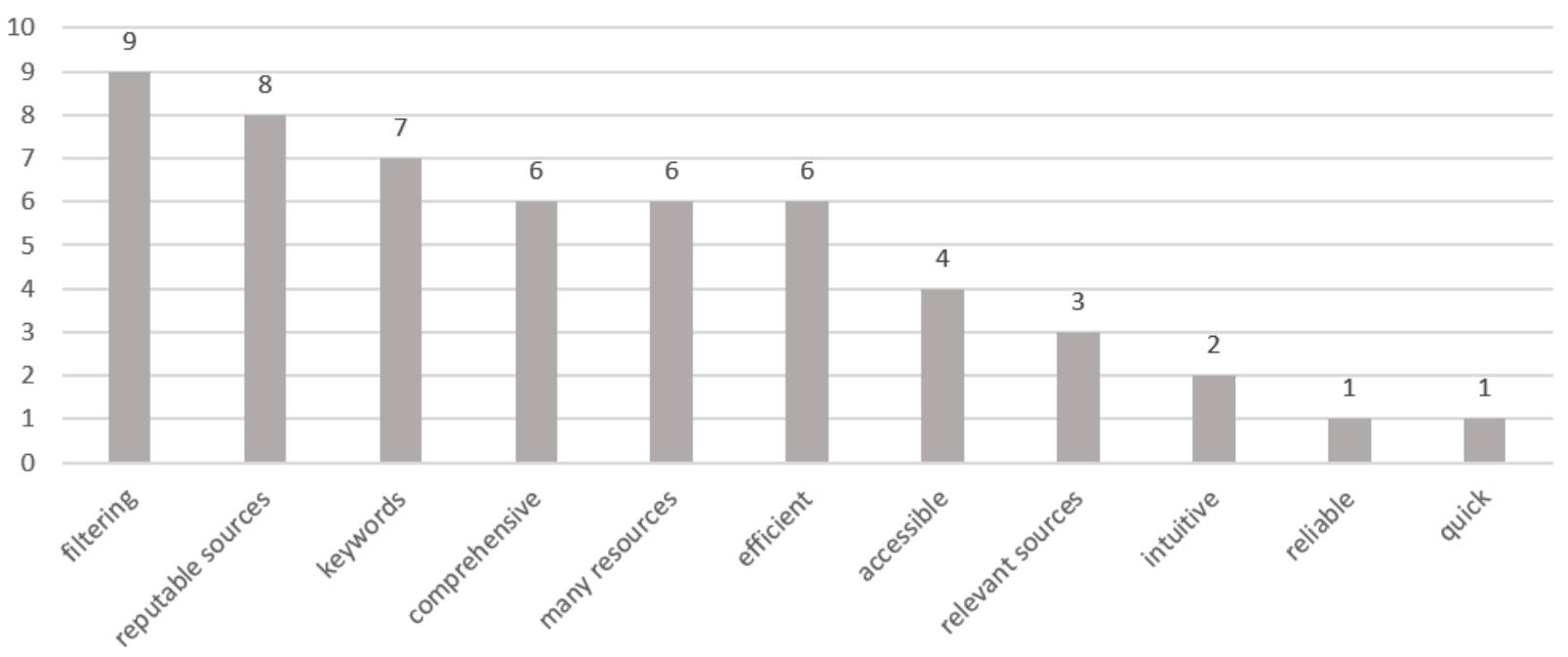

Interface easy to use

Students expressed a high level of comfort using the Primo interface to find resources for their assignment. Of the 30 students in the study, 22 indicated they had "A Lot" of comfort with the process; seven had "Some", and only one student indicated they had "Little" comfort using the box.

Single access point

Students liked the quantity and variety of information they could access based on their survey comments. Six students mentioned they liked that Primo pulled from comprehensive resource types and an additional six mentioned the quantity of resources. Some of the comments given follow:

[I]ncludes a TON of info by one simple source, allows you to narrow it more as you go.

I like that it compiles information from all the databases at once as well as other forms of information like books or newspapers that I wouldn't otherwise be able to find.

\section{Appropriate resources for academic research}

All 30 students indicated that the resources they were able to access through Primo were appropriate for their research assignment. This was largely due to their perception that Primo provided scholarly sources that required little further vetting. Students' comments on the content in Primo included:

It's kind like the main research [sic] engine google but it gives you more academic and journal style resources.

It provided search results from a variety of sources, and the sources seemed more scholarly than those you would find on google.com.

The convenience of finding these sources all in one place prompted additional comments, including: 
It got the right information in one concise location. The sources brought to the front page were all well accredited [sic] and seemed respectable. I would have utilized any of the sources in an academic paper.

\section{Successful completion of the research task}

While this study focused primarily on gauging student satisfaction with Primo, as highlighted by earlier studies, student perceptions of Primo do not always correspond with successful completion of a research task using the tool. For this purpose, the authors used a rubric to evaluate students' resources to determine how well these gathered resource would have contributed to the completion of their research prompt (see Appendix B). The research group averaged the scores from three of the authors for each of the four categories to obtain each student's overall rating of success. According to this scheme, all but four students ( 87 percent) met the study's minimum requirements for success. Of those 26, 12 performed "very successfully".

\section{Significance of findings}

Overall rates of success were measured against several variables to see if there were factors involved in the study that could have a relationship to students' performance. A Pearson's R correlation coefficient measured the significance of the students' mean success against variables: student ranking, discipline, level of comfort using Primo, level of instruction regarding Primo, and likelihood of using Primo in the future.

In the data gathered for this study, only three variables exhibited a moderate correlation with success within a 95 percent confidence interval. This is likely due to the small sample size and the fact that breaking down the 30 students into sub-groups by student ranking or discipline resulted in extremely small sample sizes - four or five students in some cases. There was a moderate relationship between student standing and very successful completion (0.284), as well as successful completion and discipline (0.426) and likelihood of using Primo in the future (0.303). These relationships suggest that a survey or study with more than 30 participants could aid further investigation of undergraduates' successful use of Primo. These results are consistent with previous studies that indicate high satisfaction with Primo despite struggling with complex tasks (Nichols et al., 2015).

\section{Conclusions}

In this study it was clear that undergraduates at KU are both aware of Primo and are using it in their research activities to a higher degree than expected. What remains to be explored is whether students understand the types of resources they are searching, and whether they are using the available features in Primo to best complete their research task. These points of uncertainty can be attributed to issues with the Primo interface as well as to students' skill level using this tool. As mentioned in the discussion, fluidity regarding the outcome of a student's research assignment plays a role in determining how pertinent resources are, which may be uncertain at the beginning of the research process when students are employing open-ended search strategies.

Because the Primo interface is relatively configurable, studying student research habits and their challenges with the interface is an opportunity for libraries to improve user success. A Primo working group at KU addressed issues with the link resolver based on feedback from this study, including improving track-back to original searches, and clarifying language on the link resolver page to help 
distinguish between links to full-text articles and links to browse journals. This is an instance, consistent with previous studies, in which students who are familiar with single-search box environments struggle to translate their experience to a web-scale discovery tool. Research indicates that students look for cues such as website domain types and concise text-based descriptions of resources that are present in Google search results but lacking in discovery tool results. Students' confusion about these inconsistencies may deter them from searching more deeply (Costello, 2016). While source type and description information exists in Primo, it appears differently than in a Google search, and may cause students to "satisfice" because the relevance of the top sources they are actually examining is not clear (Cmor and Li, 2012). Consistent with similar studies it was observed that even some students who did find and understand applicable facets did not apply them due to fear of missing other potentially relevant resources (Costello, 2016). Further usability testing can reveal insights regarding how to best arrange elements on the interface to serve user needs.

In terms of search skills and strategy, it is apparent that students are comfortable using Primo, while employing similar strategies as those used in Google and other search engines. However, instruction may be required to contextualize the scholarly search experience and guide students towards more critical evaluation of sources. As Dalal, Kimura and Hofmann note, "...teaching the mechanics [of searching with a web-scale tool] is necessary but not merely enough. We need to teach more slowly and with more repetition to ensure real mastery of even the most basic concepts (Dalal et al., 2015)." All but one student had encountered Primo at some point before this study, and the majority received instruction on how to use it either in a library instruction session or from a classroom instructor. This points to library instruction sessions as a point of further assessment to learn how discovery interfaces become (or do not become) part of students' research process. Currently, not all library instructors at $\mathrm{KU}$ teach Primo in instructions sessions. Determining why some library instructors choose to teach Primo and others do not provide an area for further research, highlighting differences in faculty and student practices and perceptions regarding web-scale discovery tools. Another area for investigation may be the teaching process of those instructors who do demonstrate Primo. Examining their approach to teaching the tool will help illuminate the moment in the process when students first encounter frustrations with Primo's interface, such as limiters, search options, or link resolvers.

Additionally, the approach to research in a web-scale discovery environment has the potential to serve students beyond a single assignment (Gustavsson and Karlsson, 2015). The fact that students struggled to articulate what types of sources they were searching in Primo lends credence to the call to focus on source evaluation, as web-scale discovery is an increasingly common part of conducting undergraduate research (Seeber, 2015). Students today refer to print materials less frequently as a way of evaluating and distinguishing among different types of resources. Before online resources, it was easy to hold up a magazine and an academic journal in an instruction session to demonstrate the difference. In an online environment, students understand the concept of a complete issue of a journal differently. Therefore, teaching the evaluation of sources is even more important than before. With the development of webscale discovery, students are exposed to a barrage of sources, and rely on specific cues and phrases from their instructors in order to determine what to cite. Library instruction needs to adapt as resources and search tools evolve. This instruction extends beyond the classroom, recalibrating how librarians communicate search and evaluation techniques at the reference desk and during research consultations - more potential entry points into undergraduates' research processes. 
The ease with which undergraduates approach tools like Primo puts large amounts of information at their disposal and makes tasks like building bibliographies and learning specific databases less important than considerations of the research process as a whole. Rather than eliminate or downplay these tasks, however, web-scale discovery tools have the potential to enhance discussion of the critical evaluation of information and the need for citation. Using search practices that students already employ meets undergraduates where they are at in terms of information seeking, moving beyond "explanations and prescriptive guidance" (Cmor and Li, 2012) to a more holistic understanding of research in the context of web-scale discovery tools. Both the present study and future inquiry can inform the library's role in contextualizing the results students retrieve and the practices they employ when using Primo or other discovery systems for research.

\section{References}

Asher, A., Duke, L., and Wilson, S. (2013), "Paths of Discovery: Comparing the Search Effectiveness of EBSCO Discovery Service, Summon, Google Scholar, and Conventional Library Resources", College \& Research Libraries, Vol. 74, pp. 464-488.

Breeding, M. (2015) "The Future of Library Resource Discovery", white paper commissioned by the NISO Discovery to Delivery (D2D) Topic Committee, Baltimore, MD.

Brett, K., Lierman, A., and Turner, C. (2016), "Lessons Learned: A Primo Usability Study", Information Technology and Libraries, Vol. 35, No. 1, pp. 7-25.

Cmor, D. and Li, X. (2012), "Beyond Boolean, towards thinking: discovery systems and information literacy", Library Management, Vol. 33, No.8/9, pp. 450-457.

Costello, D. (2016), "Search is the New Black: How Students Make Decisions." Lecture, Designing for Digital Conference, Austin, TX, April 7, 2016.

Dalal, H., Kimura, A., and Hofmann, M. (2015), "Examining Student Research Choices and Processes", in Creating Sustainable Community: ACRL 2015, Portland, Oregon, March 25-28, 2015, ALA, Chicago, pp. 668-675.

Gustavsson, J. and Karlsson, A. (2015), Web-scale Discovery Systems and Library Instruction: a Qualitative Study of Instruction Librarians' Practices and Their Perceptions of Discovery Systems' Impact on Students' Information Literacy at Three University Libraries. Thesis, Academy for Library Information Education and IT.

Hanrath, S. and Kottman, M. (2015), "Use and Usability of a Discovery Tool in an Academic Library", Journal of Web Librarianship, Vol. 9, No. 2, pp. 1-21.

Kelley, M. (2012), “Coming into Focus”, Library Journal, Vol. 17, No. 34, pp. 34.

Lown, C., Sierra, T., and Boyer, J. (2013), "How Users Search the Library from a Single Search Box", College \& Research Libraries, Vol. 74, No. 3, pp. 227-241.

Lundigren, C., Manuel, K., and Yan, M. (2015), "'Pretty Rad': Explorations in user Satisfaction with a Discovery Layer at Ryerson University", College \& Research Libraries, Vol. 76, No. 1, pp. 43-62.

Majors, R. (2012), "Comparative User Experiences of Next-Generation Catalogue Interfaces", Library Trends, Vol. 61, No. 1, pp. 186-207. 
Namei, E. and Young, Christal A. (2015), "Measuring our Relevancy: Comparing Results in a Web-Scale Discovery Tool, Google \& Google Scholar." in Creating Sustainable Community: ACRL 2015, Portland, Oregon, March 25-28, 2015, ALA, Chicago, pp. 522-535.

Nichols, A., Billey, A., Spitzform, P., Stokes, A., and Tran, C. (2014), "Kicking the Tires: A Usability Study of the Primo Discovery Tool", Journal of Web Librarianship, Vol. 8, No. 2, pp. 172-195.

Nielsen, J. (2006), “Quantitative Studies: How Many Users to Test?", available at https://www.nngroup.com/articles/quantitative-studies-how-many-users/ (accessed 13 May 2016).

Niu, T. and Hsin-liang C. (2014), "Study of User Search Activities with Two Discovery Tools at an Academic Library," International Journal of Human-Computer Interaction, Vol. 30, No. 5, pp. 422-433.

Rempel, H. G., Buck, S., and Deitering, A. (2013), "Examining Student Research Choices and Processes in a Disintermediated Searching Environment", Libraries and the Academy, Vol. 13, No. 4, pp. 363-384.

Rose-Wiles, L. and Hofmann, M. (2013), "Still Desperately Seeking Citations: Undergraduate Research in the Age of Web-Scale Discovery", Journal of Library Administration, Vol. 53, No. 2-3, pp. 147-166.

Sadeh, T. (2008), "User Experience in the Library: a Case Study", New Library World, Vol. 9, No. 1/2, pp. 7-24.

Seeber, K. (2015), "Teaching 'format as a process' in an era of Web-scale discovery", Reference Services Review, Vol. 43, No. 1, pp. 19-30.

Zhang, Y. and Wildemuth B. (2009), "Qualitative Analysis of Content", in Wildemuth, B (Ed.), Applications of Social Research Methods to Questions in Information and Library Science, Libraries Unlimited, Westport, CT, pp. 314.

\section{Appendix A: Research Assignment}

Your task is to collect a variety of resources that would be appropriate for writing a 5-10 page paper addressing the following topic:

According to a study by the Pew Research Center in 2013, 72\% of American internet users use social networking sites. Among the most popular sites are Facebook, Pinterest, Linkedln, Twitter, and Instagram. As rates of social media use rise annually, and new platforms proliferate, so to do questions about social media.

One particular area where social media has raised new questions and concerns is in the realm of privacy. The activities of social media users show what they like, who they know and are connected with, and even where they go. All of this data is information that companies or predatory individuals are interested in collecting. For this research project, you will evaluate the benefits and risks of social media in the context of privacy.

For example, should users of social media be concerned about software that tracks them, including location-based services, through social media? For those concerned about protecting their personal 
information, should the onus for privacy fall on the user or the company/platform they are using? What level of transparency should social media platforms, like Facebook, provide to their users about personal information? Should user privacy be regulated and enforced? If so, how? By whom?

Appendix B: Rubric for Determining Task Success

\begin{tabular}{|c|c|c|c|c|c|}
\hline & 4 & 3 & 2 & 1 & Score \\
\hline Relevance & $\begin{array}{l}\text { Sources are all } \\
\text { clearly related to } \\
\text { the topic. }\end{array}$ & $\begin{array}{l}\text { Most sources are } \\
\text { clearly related to } \\
\text { the topic. }\end{array}$ & $\begin{array}{l}\text { Sources cover the } \\
\text { topic, but the } \\
\text { relationship to } \\
\text { the topic is less } \\
\text { clear. }\end{array}$ & $\begin{array}{l}\text { Few, if any, sources } \\
\text { relate to the topic }\end{array}$ & \\
\hline $\begin{array}{l}\text { Variety of } \\
\text { Format }\end{array}$ & $\begin{array}{l}\text { Sources reflect an } \\
\text { appropriate } \\
\text { variety of } \\
\text { research sources, } \\
\text { mostly scholarly } \\
\text { secondary sources } \\
\text { or appropriate } \\
\text { primary sources }\end{array}$ & $\begin{array}{l}\text { Good a variety of } \\
\text { sources and most } \\
\text { are at the } \\
\text { appropriate level } \\
\text { for this purpose }\end{array}$ & $\begin{array}{l}\text { Selected sources } \\
\text { are less varied but } \\
\text { most are at the } \\
\text { appropriate level } \\
\text { for the purpose }\end{array}$ & $\begin{array}{l}\text { Sources are mostly } \\
\text { one source type } \\
\text { (news articles, } \\
\text { scholarly journals, } \\
\text { websites) }\end{array}$ & \\
\hline $\begin{array}{l}\text { Variety of } \\
\text { Content }\end{array}$ & $\begin{array}{l}\text { Sources do not } \\
\text { repeat the same } \\
\text { information and } \\
\text { are in } \\
\text { conversation with } \\
\text { each other }\end{array}$ & $\begin{array}{l}\text { A few sources } \\
\text { cover the same } \\
\text { content but are } \\
\text { still in } \\
\text { conversation with } \\
\text { each other }\end{array}$ & $\begin{array}{l}\text { Some sources are } \\
\text { redundant, or not } \\
\text { in conversation } \\
\text { with each other }\end{array}$ & $\begin{array}{l}\text { Most sources } \\
\text { repeat information, } \\
\text { or do not relate to } \\
\text { each other }\end{array}$ & \\
\hline Potential & $\begin{array}{l}\text { Source adds } \\
\text { greatly to } \\
\text { research } \\
\text { potential, few if } \\
\text { any additional } \\
\text { sources needed }\end{array}$ & $\begin{array}{l}\text { Some sources are } \\
\text { overly broad, may } \\
\text { require a small } \\
\text { amount of } \\
\text { additional } \\
\text { research }\end{array}$ & $\begin{array}{l}\text { Most sources are } \\
\text { overly broad, } \\
\text { additional } \\
\text { research would } \\
\text { be necessary }\end{array}$ & $\begin{array}{l}\text { Sources would not } \\
\text { be sufficient to } \\
\text { complete the } \\
\text { assignment }\end{array}$ & \\
\hline \multicolumn{6}{|c|}{ 0-8 points: unsuccessful } \\
\hline
\end{tabular}

Appendix C: Comments from what Students Liked/Disliked about Using Primo

\begin{tabular}{|l|l|l|l|}
\hline $\begin{array}{l}\text { Student } \\
\text { Status }\end{array}$ & Major & $\begin{array}{l}\text { What did you like about using the library } \\
\text { search box? }\end{array}$ & $\begin{array}{l}\text { What did you find frustrating about using the } \\
\text { library search box? }\end{array}$ \\
\hline Fresh. & Pre-pharmacy & $\begin{array}{l}\text { It seemed to have incorportated all of the } \\
\text { databases. }\end{array}$ & Nothing really. \\
\hline
\end{tabular}




\begin{tabular}{|c|c|c|c|}
\hline Jun. & Finance & $\begin{array}{l}\text { There was a multitude of reputable } \\
\text { resources and articles to search through. }\end{array}$ & $\begin{array}{l}\text { Occasionally there was a link(s) to an article } \\
\text { that would not work or that required extensive } \\
\text { effort to get to the actual article. The article } \\
\text { was not always easy to find. / }\end{array}$ \\
\hline Sen. & chemistry & $\begin{array}{l}\text { It's kind like the main reserach engine } \\
\text { google but it gives you more academic and } \\
\text { journal style resources. Of course you can } \\
\text { also use advanced search to filter out all } \\
\text { the information you don't need and find } \\
\text { the resource more directly and effectively. }\end{array}$ & $\begin{array}{l}\text { It doesn't give you first-hand news article or } \\
\text { resources from more informal sites like } \\
\text { personal blogs and colunmns, which can } \\
\text { sometimes be really effective for research. }\end{array}$ \\
\hline Soph. & $\begin{array}{l}\text { Computer } \\
\text { Engineering }\end{array}$ & $\begin{array}{l}\text { I like that you can tell it to look for specific } \\
\text { words. This is helpful if a keyword or } \\
\text { phrase is not helping you find the sources } \\
\text { that you need. }\end{array}$ & $\begin{array}{l}\text { The advanced search option isn't really visible. } \\
\text { You have to look for it to find it. I probably use } \\
\text { the advanced search tab the most. }\end{array}$ \\
\hline Jun. & Pharmacy & $\begin{array}{l}\text { It was easily accessible on the front page } \\
\text { of the libraries website. }\end{array}$ & It was difficult to exclude words/ \\
\hline Jun. & Visual Art & $\begin{array}{l}\text { It uses the keywords of your search topic } \\
\text { to find articles with those same keywords } \\
\text { off the bat, which I think is very helpful } \\
\text { and then there's always the option of } \\
\text { using 'advanced search' to get even more } \\
\text { specific. }\end{array}$ & $\begin{array}{l}\text { Nothing really because it is kind of straight } \\
\text { forward. Sometimes I found that using other } \\
\text { words other than the specific topic you are } \\
\text { looking for (ex: the, of, it, etc) that that may } \\
\text { interfere, but not usually. }\end{array}$ \\
\hline Fresh. & $\begin{array}{l}\text { Mathematics } \\
\text { (bs) }\end{array}$ & $\begin{array}{l}\text { includes a TON of info by one simple } \\
\text { source, allows you to narrow it more as } \\
\text { you go }\end{array}$ & $\begin{array}{l}\text { Sorts by "relevance" but not exactly sure what } \\
\text { that pertains to, the amount of sources it brings } \\
\text { up is helpful, but also overwhelming at times. }\end{array}$ \\
\hline Fresh. & Microbiology & $\begin{array}{l}\text { I am able to type in general search terms } \\
\text { and have a wide variety of results. I can } \\
\text { sort through the results based on a } \\
\text { number of factors, like date, easily. I can } \\
\text { also use the "Full Text Online" option to } \\
\text { make sure the source will be available } \\
\text { when I want/need it. }\end{array}$ & $\begin{array}{l}\text { I am not always sure that the source I want to } \\
\text { use will be available immediately or on } \mathrm{my} \\
\text { computer. }\end{array}$ \\
\hline Jun. & Accounting & $\begin{array}{l}\text { I liked that I knew the sources would be } \\
\text { reliable and that I would not have to do } \\
\text { more work to determine the validity of } \\
\text { the sources. }\end{array}$ & $\begin{array}{l}\text { Most of the articles I had to get the full text to } \\
\text { get a better understanding of what was in } \\
\text { them. Some of them did include brief } \\
\text { synopsises in the details section which was very } \\
\text { helpful. }\end{array}$ \\
\hline Jun. & $\begin{array}{l}\text { Strategic } \\
\text { Communicatio } \\
\text { ns Journalism } \\
\end{array}$ & $\begin{array}{l}\text { I like the variety of sources that come with } \\
\text { putting different key words together. }\end{array}$ & $\begin{array}{l}\text { Sometimes I do not know how to use "and" or } \\
\text { "or" or other keywords that are said to expand } \\
\text { your search. }\end{array}$ \\
\hline Sen. & Psychology & $\begin{array}{l}\text { That it mostly gives me access to scholarly } \\
\text { articles that are relevant to what I'm } \\
\text { researching. }\end{array}$ & $\begin{array}{l}\text { Occasionally the searches bring up articles that } \\
\text { very vaguley relate to what I was needing. Also, } \\
\text { sometimes it's frustrating to open articles that } \\
\text { don't really lead you where you need. }\end{array}$ \\
\hline Soph. & $\begin{array}{l}\text { Communicatio } \\
\text { n Studies and } \\
\text { Journalism }\end{array}$ & $\begin{array}{l}\text { I liked using the library search box } \\
\text { because it gave relevant search results } \\
\text { with more professional journalistic articles } \\
\text { than a typical Google search would. }\end{array}$ & $\begin{array}{l}\text { The frustrating part was finding specific enough } \\
\text { articles about what I was searching for. }\end{array}$ \\
\hline Fresh. & Neurobiology & $\begin{array}{l}\text { It is streamlined and lets me have access } \\
\text { to hundreds and thousands of articles, } \\
\text { books, etc... with a few clicks. }\end{array}$ & Nothing. \\
\hline
\end{tabular}




\begin{tabular}{|c|c|c|c|}
\hline Soph. & $\begin{array}{l}\text { Journalism } \\
\text { and Sociology }\end{array}$ & $\begin{array}{l}\text { I like that it compiles information from all } \\
\text { the databases at once as well as other } \\
\text { forms of information like books or } \\
\text { newspapers that I wouldn't otherwise be } \\
\text { able to find. }\end{array}$ & $\begin{array}{l}\text { There seem to be a lot of duplicate responses } \\
\text { from various databases carrying the same } \\
\text { information. I wish there was a way to limit } \\
\text { your search as to only see one result of each } \\
\text { article, etc. Also, overall using the box is a little } \\
\text { overwhelming if you don't have a set idea of } \\
\text { what it is you're searching for. }\end{array}$ \\
\hline Jun. & $\begin{array}{l}\text { Spanish/Pre- } \\
\text { Nursing }\end{array}$ & $\begin{array}{l}\text { I like that you can tailor the searches and } \\
\text { use Boolean searches to find the results } \\
\text { you're looking for. }\end{array}$ & $\begin{array}{l}\text { Occasionally, I'll run across an article link that } \\
\text { doesn't work properly, but it's usually fairly } \\
\text { simple to go into the journal and find that. I } \\
\text { also notice that some articles may show up as } \\
\text { multiple results and though it wasn't too bad } \\
\text { today, it can take up several pages of results in } \\
\text { other searches. }\end{array}$ \\
\hline Fresh. & $\begin{array}{l}\text { Middle Level } \\
\text { Mathematics } \\
\text { Education }\end{array}$ & $\begin{array}{l}\text { I liked how the search box was divided } \\
\text { into categories like articles, dissertations, } \\
\text { etc. For some assignments in the past, I } \\
\text { have had to gather "scholarly" articles as } \\
\text { evidence so the dissertation section of the } \\
\text { search box was particularly helpful. I also } \\
\text { liked how I could specify the dates I } \\
\text { wanted the articles to be written by. I was } \\
\text { looking for the most recent pieces of } \\
\text { evidence to support my claim since social } \\
\text { media and privacy concerns that come } \\
\text { with it is always changing. }\end{array}$ & None. \\
\hline Fresh. & $\begin{array}{l}\text { Business } \\
\text { management }\end{array}$ & $\begin{array}{l}\text { Allowed me to look at book online and } \\
\text { search with in the book with is very } \\
\text { helpful }\end{array}$ & $\begin{array}{l}\text { It brought me right to what I needed I didnt feel } \\
\text { frustrated }\end{array}$ \\
\hline Jun. & $\begin{array}{l}\text { Journalism -- } \\
\text { news and } \\
\text { information }\end{array}$ & $\begin{array}{l}\text { It's easy to find relevant results, especially } \\
\text { because the default search filter is "most } \\
\text { relevant." }\end{array}$ & $\begin{array}{l}\text { When looking for more recent articles and } \\
\text { sources, you have to sacrifice the relevancy, } \\
\text { which can make research more difficult when } \\
\text { you're getting sources that are newer, but have } \\
\text { little to do with the topic you're looking at. } \\
\text { Because you have to change your filter, you're } \\
\text { giving up the usefulness of the "most recent' } \\
\text { filter. }\end{array}$ \\
\hline Soph. & $\begin{array}{l}\text { Architectural } \\
\text { Engineering }\end{array}$ & $\begin{array}{l}\text { I like that you can specify what kinds of } \\
\text { resources it finds for you, such as 'Articles } \\
\text { and Databases.' }\end{array}$ & $\begin{array}{l}\text { Its frustrating that in order for your finds to be } \\
\text { most relevant, you have to type in what your } \\
\text { searching for in a specific manner. }\end{array}$ \\
\hline Fresh. & Pre-nursing & $\begin{array}{l}\text { You can limit our what you don't want to } \\
\text { see such as books, different languages, } \\
\text { etc. }\end{array}$ & $\begin{array}{l}\text { Not in this study, but in past experiences I } \\
\text { would use terms that were specfic to my area } \\
\text { of interest and there would be nothing that } \\
\text { showed up. I know you can't get too speficifc, } \\
\text { but sometimes the topic assigned is very } \\
\text { specific and there is no way of getting around } \\
\text { that. / / Also, sometimes the links don't work } \\
\text { or they send me to a different website that I } \\
\text { have to search for the article again rather than } \\
\text { just pulling up the article in the first place. }\end{array}$ \\
\hline
\end{tabular}




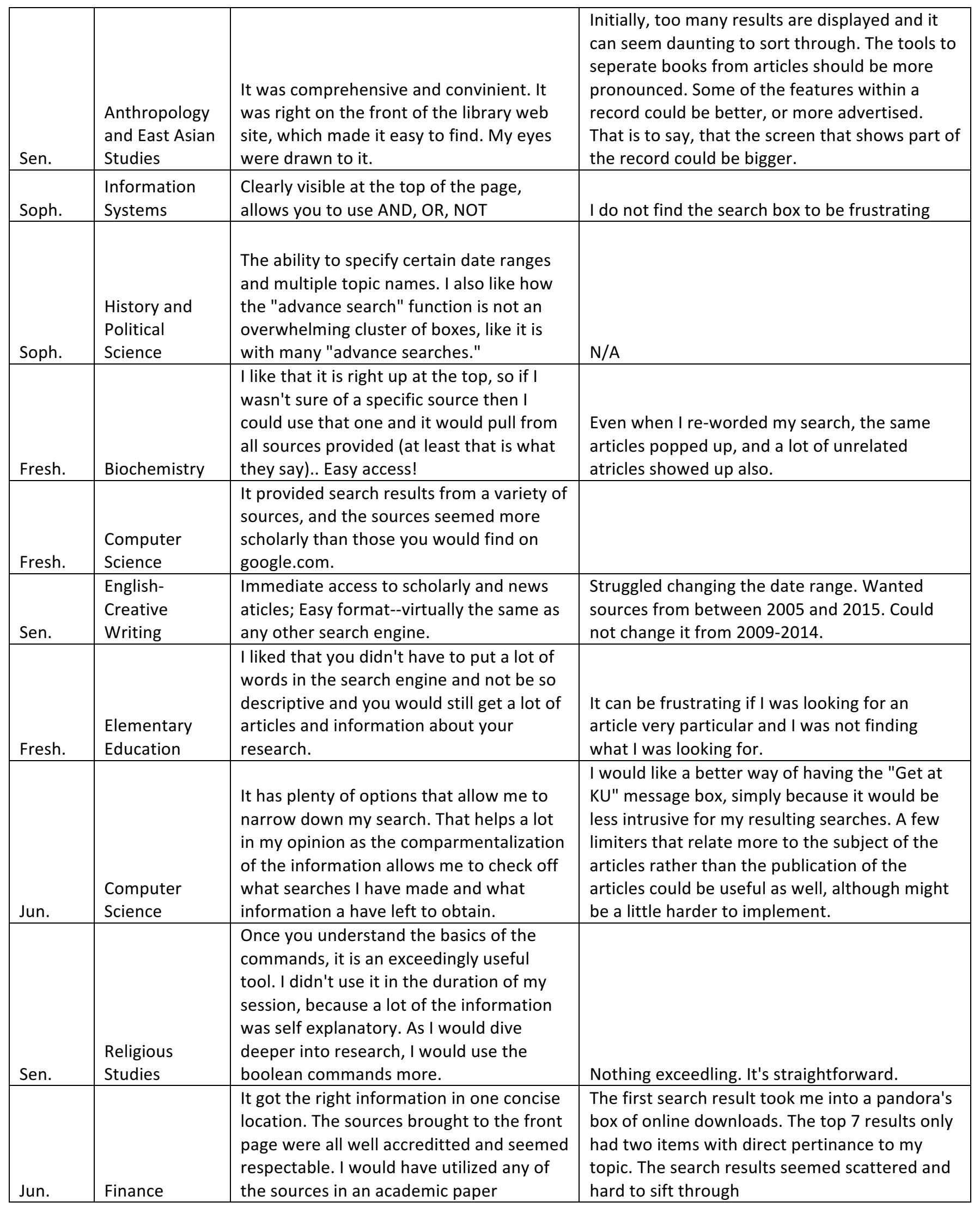


Primo; Undergraduate Research; Usability 19 